\title{
Multi-Dimensions of Food Insecurity in Chiang Mai, Thailand: A Socio-Economic Examination of Agricultural Production
}

\author{
Wanwarang Krittaput ${ }^{1}$ \\ ${ }^{1}$ Sustainable Land Use and Natural Resource Management, Chiang Mai University, Chiang Mai, Thiland \\ Correspondence: Wanwarang Krittaput, Sustainable Land Use and Natural Resource Management, Chiang Mai \\ University, Chiang Mai, Thiland.
}

Received: August 10, 2018

doi:10.11114/ijsss.v7i5.4450
Accepted: July 26, $2019 \quad$ Available online: August 13, 2019

URL: https://doi.org/10.11114/ijsss.v7i5.4450

\begin{abstract}
Multi-dimensions of food insecurity are varied and complex in negative production situations and related issues. The change to commercial agricultural production presented as a socioeconomic and environmental transition to food insecurity in a Ban Pa Phai, Chiangmai, Thailand. Farmers were faced with many stressors such as decline in crop and natural food acquisition, constraints in ecological and natural resources, unpredictable prices of agricultural products and changes in production processes. The community adapted to these crises with initiative and attempted to become self-reliant and collaboratively manage other agents. Initiation groups were formed both in-farm and off-farm to create more food security and additional income Farmers work as a group to creatively adapt to new technologies and showed high levels of improvement in view of both officials and researchers. Adaptive management involves awareness of farming food crises and the capacity of community leaders to instigate changes. Kinship in bonding relationships were demonstrated among farming households with mutually coherent collective effort. Management collaboration between the community and external organisational support is vital to solve problems in a holistical manner.
\end{abstract}

Keywords: food insecurity, collaborative management

\section{Introduction}

\subsection{Introduce the Problem}

Food security in global food systems is often complex. New economic environments for agricultural production change supportive food stabilisation policies to global market chains. Policies concerning production and trades in global context and commercial production have become mainstream regimes (Kerdnoi, 2014).

The transformation from subsistence farming to market-oriented production requires farming households to adapt and change. Biodiversity loss occurs due to excessive use of fertilisers and pesticides, while land degradation is exacerbated through increased focus on mono-cropping (Eakin, 2007).A limited and narrow focus on production ultimately defeats itself by destroying the resource base on which agriculture depends (Rosset, 2008). Moreover, food security in a mainstream economic application and small food producers do not follow these standards. In addition, food security interventions both in form of national level programmes and international efforts via emergency assistance through support programmes can also further distort food markets and suppress local production (Hendrix, 2012)

Food security implementation as a mainstream policy often focuses on the interconnection between poverty, malnutrition, hunger and micronutrient deficiencies (Gragnolati, 2005) on the demand side of consumers. Vulnerable groups for food insecurity are those with reduced calorie intake per captita per day. Food producers are faced with multi-dimensional problems of food security. Thailand is an agricultural product exporter. The volumn of agricultural exports is proof of the progressive achievement of agro-businesses and government efforts in supporting macro market. Thailand is also a globally important rice exporter at 11,674,331 million tonnes, generating 175,161 million baht in value in 2017 (Thai Rice Exporter Association, 2018). Empirical evidence suggests that chemical exposure to pesticide intoxification is major health problem for Thai farmers with an increasing trend (Tawatsin, 2015). So, trade-based food security is inadequate to tackle these problems (Winfuhr \& Josen, 2005)

Macro-micro linkages of mainstream food production and practical effects have shifted the perspective to multi-dimensional aspects of food insecurity. In other words, bridging the gap between natural and social dimensions 
requires conceptual combination. Small-scale farmers as vulnerable people in food systems on the supply side should not be neglected. Their exposure to resource bases and production enhance their capacity to adapt to crises proactively. Crocker (2008) suggested that the ability of a person to pursue and achieve goals was based on the capacity to be food secure so building resilience as a long-term perspective should be seen as a priority element of mechanisms.

Here, the changing agricultural dynamics in Ban Pa Phai, a peri-urban agricultural community in Chiang Mai, Thailand were investigated. Results indicated that food insecurity effected not only individual farmers but also the entire community in multi-dimensional aspects.

The objectives were first to assess the development and current situation of multi-dimensional food insecurity and second to investigate adaptive community behaviour to address the food insecurity crisis. Results illustrated how mutual food production patterns have been impacted by commercial production processes which have contributed to food insecurity through socio-economic contexts. Bridging the gap requires interaction between food production under a mainstream food regime, involving farmers who are both producers and consumers to alleviate food insecurity. Furthermore, how agricultural households have instigated through adaptive production behaviours using collaborative management is also discussed.

\subsection{Relevant Scholarship}

A narrow focus on agricultural supply, productivity and technologies still dominates international food security. Conventional agricultural management deals with food security through productivity and harvesting technologies using inputs such as insecticide, pesticide and irrigation. Over-promotion of export-oriented agriculture places small farmers in a vulnerable situation (Phungpracha et al., 2016).Therefore, adopting new technologies can adversely impact food producers. Competitive inequality also constrains small food producers. Food availability and accessibility in world markets are defined as the ability to acquire available food from earnings. Thus, smallholders and landless peasants often incur high incidences of food insecurity (Barraclough, 1991)

Furthermore, changing from traditional agricultural systems to commercial production transforms the benefits of natural commodity resources. Natural degradation increases and in some cases scientific and technological approach do not work well, even making problems worse. Failure may related to focus on wrong kinds of sustainability (Berkes \& Folkes, 1998).Agricultural commercialisation is associated with an increase in pesticide use (Srisomboon, 2012).Thai farmers depend on agrochemicals to sustain productivity while some health problems have arisen (Thai National Food Committee, 2012).Farmers are adversely impacted by health symptoms related to crop cultivation and farm activities, with increasing prevalence of respiratory tract diseases, muscle systems and skin irritation (Sapbamrer, 2014).

The dynamics of food system require a comprehensive understanding of food insecurity through detailed case studies. Food security studies require more than a snapshot in time and need to consider prolonged periods of change. Timelines are used to analyse the changing dynamics. Memories as accumulated personal experiences are useful to provide system history as sources for self-organisation and resilience. Ecomomic, social and environmental components are used to narrate interactions with disturbances in space and time (Nystrom \& Folke, 2001)

Producers are actor-oriented paradigms who emphasise on adaptation through collaborative management in food insecurity issues. Adaptation focuses on enhancing capacities to face change. Importantly, adaptive management emphasises learning-by-doing and feedback learning (Gunderson, 2006).Moreover, participation by local people in the relief of stress is positive because this helps to alter mindsets from the role of victim to that of decision-maker. Here, collaborative management was determined as a platform of adaptation to resolve the food crisis and reduced production of Ban Pa Phai. Because of complexities of food insecurity and other related constraints, collaborative management between the community and external supportive organisations should be encouraged. Analysis of food security at the household level offers meaningful insight to assess complex food security issues and how to operationalise the problem at the micro level.

Key terms used in this study are defined as follow:

Food insecurity: A situation that exists when people lack secure access to sufficient amounts of safe and nutritious food for an active and healthy life (FAO, 2018)

Collaborative management: Cooperation in action processes of organisational groups with mutual arrangements for solving problems that cannot be easily achieved by one organisation to determine officially or unofficial mutual goals (Agranoff \& Mcquire, 2003).Collaborative management is vital for a community as the capacity to work together and realise positive social, economic and environmental outcomes (Etuk, 2012)

Adaptive capacity : The ability of systems, institutions and humans to adapt to new options when faced with crises by making proactive and informed choices concerning alternative livelihood strategies bases on a comprehensive understanding of changing conditions (FAO, 2015) 


\section{Method}

The farming community of Ban Pa Phai, Chiang Mai was selected as the study area and assessed and examinated as a food insecurity exposure location. Farmers' livelihoods as food producers have become vulnerable because of the shift to commercial production. Public awareness, production initiatives and enabling factors to tackle the crisis involved setting guidelines for adaptive mechanisms in food insecurity at the micro level. Interviews and field surveys were conducted from September 2014 to August 2015

\subsection{Participant Characteristics}

Research participants were classified into three groups.

First, seven key informants (two leaders and five senior citizens).Second, participants were drawn from $30 \%$ of all farming households (60 out of 201) engaged in agricultural production for more than 20 years (Krejcie \& Morgan, 1970).This group was divided into two subgroups as 1) Thirty farmers who had high perception and adaptation and 2) Thirty farmers who had normal perception and adaptation. Perception was defined by key informants in term of scaling up food security using positive and successful farm practices and third, government officials and researchers who supported the learning and adaptation processes of farmers.

\subsection{Sampling Procedures and Sample Size}

A documentary study coupled with in-depth interviews was used to select leaders and senior citizens in terms of socio-economic contexts related to the dynamic of food insecurity. Questionnaries were circulated to the two groups of farmers which focused on their adaptive production behaviours and learning process through self-learning and collaborative management with organisation. In-depth interviews were also conducted with government officials and researchers to emphasise the achievements of collaborative management by the community.

A crises assessment through a socio-economic history timeline was used to reflect the multi-dimensions of food insecurity including the pre-crisis phase (before 1966), crisis phase (1966-1978) and adaptation to crisis phase (1979 onwards)

\subsection{Measures}

Questionnaires concerning adaptive production behaviours were analysed into three as high level (60\% of total practicing households), moderate (40-59\% of total practicing households) and low (less than $40 \%$ of total practicing households) (Creswell \& Clark, 2007).Farming activities of the high-perception farmer's group were assessed by frequency counts and percentage using academic techniques.

\section{Results}

\subsection{Socio-Economic Dynamics Related to Context}

During the pre-crisis phase, Ban Pa Phai was a small agricultural community in a rural area of Chiang Mai. Reorganisation of Payap Canton in 1899 heralded independent peasants and land tenure system (Sethakul, 2009).An abundance of natural food from landscape and forests maintained the people. Exchange of agri-food surplus was conducted with nearny communities e.g. Ban Pa Miang, Ban Pok, Ban Mae Torn by cattle merchants. sticky rice, dried fishes, chillie and edible forest plants were key food products exchanged for Assam tea from other communities. Farmers in Chiang Mai-Lamphun Basin area were stimulated to plant rice in response to market needs with supportive operations of northern railway and expansion of road connections to Chiang Mai. However, Ban Pa Phai farmers still depended on subsistence production due to their inconvenient location.

Subsequently, as a results of socio-economic interaction with Chiang Mai, Ban Pa Phai developed into a peri-urban agricultural community which then gradually changed from subsistence to commercial agricultural production during the crisis phase.since1967, farmers have expanded farming areas and increased commercial rice production in response to higher market demand. Improvement in accessibility through the construction of an asphalt road benefitted the distribution of farmers' products, especially glutinous rice and new key crops such as garlic. Moreover, tobacco cultivation became vital to Chiang Mai economy with large amounts of revenue from agricultural commerce during the late 1930s to 1960s.The influx of modern technologies generated new farm inputs and techniques as small tractors, chemical pesticides and fertiliser introduced by stated officials. These new production patterns and tools endangered agricultural households to become indebted, while pest and plants diseases severely impacted on yields. Meanwhile, implementation of National Economic Development Plans 1-4 focused on increasing food production. Loans were allocated for farmers with increased use of agri-chemicals and improvement of infrastructures as roads and reservoirs extended farm production areas and supported product transportation (Thepent, 2009).

During the third phase, although the study area had become famous for its garlic production, farmers were faced with diverse problems such as higher operating costs and fluctuation of prices for farm products. Additionally, the improved 
roads, new irrigation systems and access to information widened community agricultural production. Significantly, for production and resources bases crises, agricultural production and occupational training are related to various actors.

3.2 Dynamics of Food Insecurity in Multi-Dimensions

Table 1. Dynamics of food insecurity in multi-dimensions

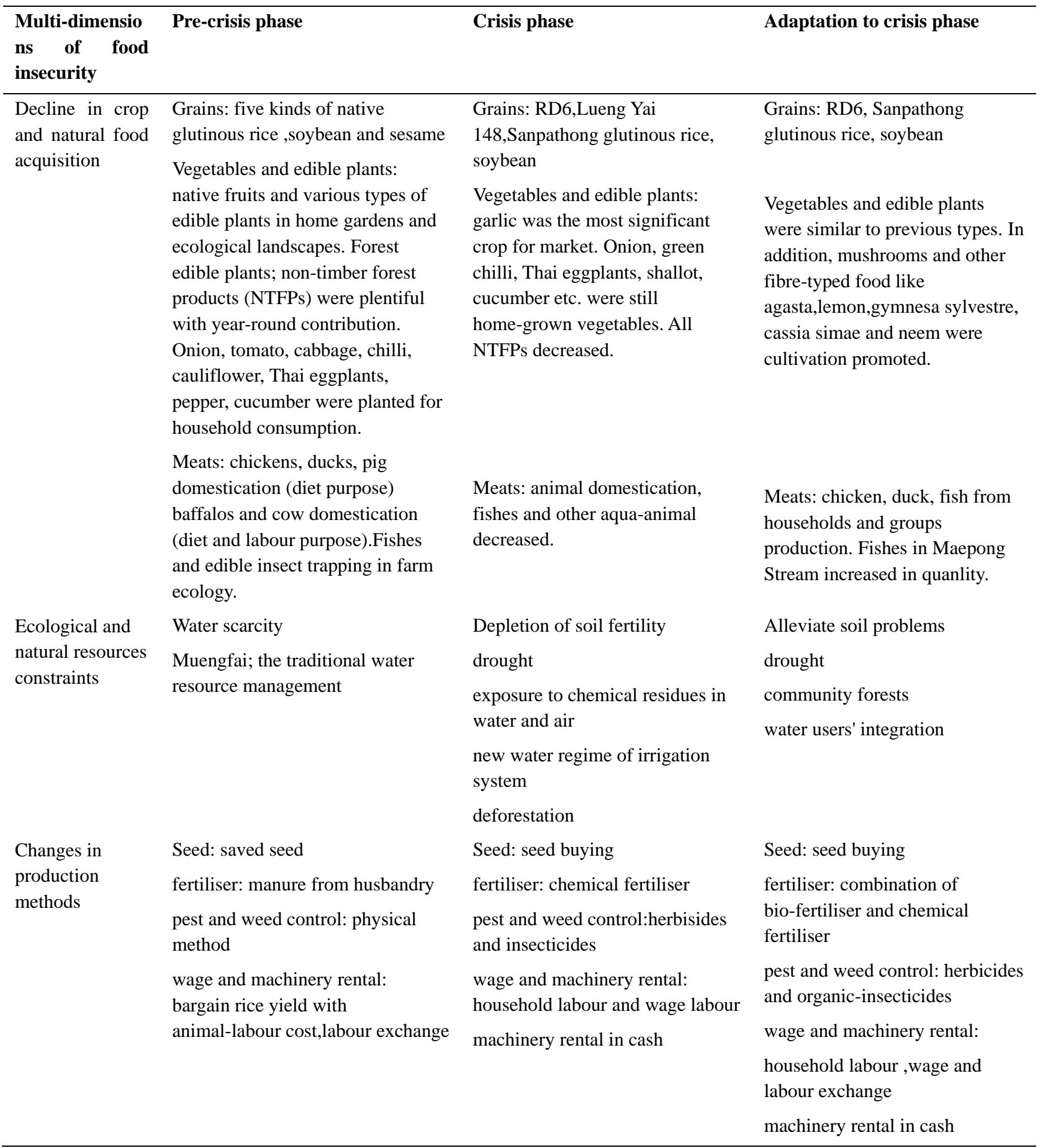

The dynamics of food insecurity in Ban pa Phai are shown in Table 1. Crops and natural food acquisition have obviously changed. In the pre-crisis phase with subsistence production, farming households were secure in food availability and diversity. Natural food sources and farm activities provided types of food as grain, fibre and meat. Farming, fishing and hunting and gathering activities sustained local food. Five Native rice (Khao) varieties as Khao 
Lao, Khao Kaew, Khao Pha, Khao Meunong and Khao Kum were main staples for household consumption. Interviews with NTFPs harvesters identified edible of Ban Pa Phai presented in abundance such as 1.Star Gooseberry (Leptonycni heteroclita), 2. Tiger's Herb (Hydrocotyle javnica Thumb.), 3. Elephant Ear (Colocasi esculenta var.aquatilis), 4. Plu Kaow (Houttuynia cordata Thumb.), 5. Benghal Day Flower (commelina nenghalensis L.), 6. Hog Plum (Spondias pinnata L.F kurz.), 7. Por Kaa Tee Mear (Selaginella argenta Spring.), 8. Oak Fern (Dryopteris amboinensis), 9. Phak Naam (Lasia spisa L.Thwaites) 10. Rai bamboo shoot (Gigantochloa albociliata Munro Kurz.), 11. Bong bamboo shoot (Bammusa nutans Wall.Ex Munro), 12. Ruak bamboo shoot (Thyrsostachys siamesis Gamble), 13. Sweet bamboo shoot (Bambusa Sp.), 14. Log White Fungi mushroom (Lentinus polychorous Lev.), 15.Jew's Ear mushroom (Auricuria auricula Judae.), 16.Barometer Earthstars (Atraeus hygrometricus Pers Morgan), 17.Termite mushroom (Termitomyces fuliginosus Heim.), 18.Kamin mushroom (Craterellus sp.) 19. Greenish mushroom (Rusula virescens Fr.) and 20.Bolete (Thaeogyroporus porentosus berk.ET. Broome).

NTFPs supplied food with year round production due to their diversity. Domestication of chickens, ducks, cowsand buffalos were found in households production as well as planting home-grown vegetables by simple methods. Food sharing among villagers benefitted both food acquisition and social relationship bonding. Farmers relied on commercial production, however during the second phase farm products reduced in variety due to the incentive focus on market rice and crops. Native rices were replaced by new rice varieties with better suitability to new harvest machines and market demand. Native fruit production also decreased. Ecological stressors such as temperature and humidity changes and forests fires are harmful to availability of NTFPs and all decreased. However, forest conservation strategies as forest fire monitoring and bamboo planting benefitted NTFPs yield. NTFPs nos.1,4,8,9,12,18,19 1.Star Gooseberry (Leptonycni heteroclita), 2.Tiger's Herb (Hydrocotyle javnica Thumb.),3.Elephant Ear (Colocasi esculenta var.aquatilis), 4. Plu Kaow (Houttuynia cordata Thumb.), 5 Benghal Day Flower (commelina nenghalensis L.),6. Hog Plum (Spondias pinnata L.F kurz.), 7.Por Kaa Tee Mear (Selaginella argenta Spring.), 8.Oak Fern (Dryopteris amboinensis), 9.Phak Naam (Lasia spisa L.Thwaites) became abundant. Interestingly, nowadas, NTFPs nos.1,8,9,13,14,15,20 were household domesticated for subsistence and trade to local vendors.

Drought and increased water scarcity affected farm yield. Chemical residues in water sources reduced aqua-food as fishes. Chemical use in farming also caused acid soil degradation. From 1982 to 2000 ,acid soil was a crucial stressor on production due to 40 years of chemical use in farm activities. Nowadays, farmer still use chemical fertiliser and other chemical substances in farming are considered as more traditional methods to optimize production. Thus, production in terms of adaptation of chemical technologies to deal with ecological aspects did not always succeed. Food insecurity was exposed in multi-dimensions as many stressors. Many local farming livelihoods as water management, seed saving and farm labour exchange were lost. Irrigation systems supported crop water supply but were not effecient for varied planting periods. Labour exchange reduced as commercial production increased. Health problems increased due to chemical exposure to farmers and villagers as evidenced by blood testing in 2003. Only 5 out of 102 villagers had normal level in blood tests. Traditional herbs were used to improve health. Price fluctuation still existed; however, to cope with agricultural products e.g. garlic surplus, people joined together in food processing. Because of this complex situation in food security, farmer adapted to the crisis by changing production behaviours. They reverted to organic methods for pest and weed control, reintroduced the traditional labour exchange culture, rediscovered traditional medicine methods and adopted forests conservation and water source conservation to improve the availability of food, safe-food issues, ecological conditions, health status and production cost. Importantly, adaptive production behaviours of Ban Pa Phai farmers related to collaborative management with the government extension services and support from research and educational organisations as shown in Table2.

\subsection{Adaptive Production Behaviours and Collaborative Management}

Table 2 shows the adaptive behaviours between the two groups. Growing vegetables for household consumption was the main agricultural practice to support food security by both groups. Furthermore high implementation of bio-fertiliser utilisation and associating in agricultural groups was exhibited by farmers in high perception group. Diversifying food production enhanced the livelihood of farming households. Moreover,positive support for alternative methods of pest control improve health, enviromental and economic concerns related to agricultural production. Farmer initiative many adaptive production behaviours. Examples of initiative were farmers originating self-producing bio-fertiliser from rice stubble and fermenting sawdust and weeds to improve acid soils. Leading farmers trialed pilot plots and exchanged knowledge with other farmers. 
Table 2. Adaptive production behaviours of farmers

\begin{tabular}{lcc}
\hline Adaptive production behaviours of farmers & $\begin{array}{c}\text { farmers with high } \\
\text { perception }\end{array}$ & $\begin{array}{c}\text { Farmers with normal } \\
\text { perception }\end{array}$ \\
\hline Growing vegetables for household consumption & high & high \\
Growing fruit for household consumption & moderate & low \\
Raising livestock for household consumption & moderate & low \\
Practicing agricultural production in varied & low & low \\
types of plants & high & low \\
Implementation of mixed agriculture & moderate & low \\
Utilising bio-fertiliser in farming & high & low \\
Utilising herbal pesticides in pest management & & low \\
Associating in community agricultural groups &
\end{tabular}

Table 3. Farming activities of the high-perception farmer's group through academic technique transmission

\begin{tabular}{lcc}
\hline \multicolumn{1}{c}{ Farm activities } & Participants & Percent \\
\hline Livestock activities & 4 & 13.33 \\
Raising cattle & 15 & 50.00 \\
Raising chickens & 5 & 16.67 \\
Raising pigs & 6 & 20.00 \\
Raising frogs & 2 & 6.67 \\
Raising ducks & 1 & 3.33 \\
Growing forage plants & 13 & 43.33 \\
Fishery activities & & \\
cultivation & 20 & 66.67 \\
Field crop cultivation & 12 & 40.00 \\
Fruit cultivation & 2 & 6.67 \\
Vegetables cultivation & & \\
Agricultural processing & 11 & 36.67 \\
Fruit processing & 8 & 26.67 \\
Field crop processing & 4 & 13.33 \\
Vegetable processing & & \\
\hline
\end{tabular}

Transmissions in farm practices and techniques were achieved through collaborative management between the community and external organisations including Huai Hong Khrai Royal Development Study Centre, Chiang Mai University and Mahidol University. Community leaders assumed important roles in mobilising the learning process of farmers. Through transmission of farm practices, farmer gained domestic food sources. Initiation groups were formed both in-farm and off-farm to create more food security and additional income. Moreover, financial and livelihood supports related to food production were also included, for example saving groups, livestock domestication groups, fishery groups,frog domestication groups, native food cooking groups and mushroom cultivation groups. In regard to farmers' opinions on collaborative management, former projects were not consistent with their interests. The projects had low impact on participants because they did not apply practical knowledge. However, over past 10 years, many projects have responded to needs and potential mutual brainstorming is flexible and continual improvement of strategies furnishes both organisational goals in extension projects and community capacity to solve problems. Good examples of holistic production management by farmers included sharing breeding and fodders product among producers for cost-saving. Moreover, community volunteers provided veterinary services and self-support. Through collaborative management, extension projects raised their effective impacts and gave farmer more self-reliance on food security. 
Farmer-to-farmers knowledge and skill exchanges between experienced farmers and others progressively up-scaled adaptive capacity.

Government officials and researchers were of the opinion that farmers' adaptive learning utilised farm land and increased productivity and food through collaborative learning. Moreover, working as team with outside organisations was positive step which improved production capacity and agricultural capital.

\section{Discussion}

Multi-dimensions of food insecurity include complex situations of production, natural contraints and also regime forces. Commercial production is linked to producer food security by many aspects including diversity of food, means of production, natural resource base changes and health problems. To analyse food insecurity dynamically, flashbacks to local people' memories may offer rich information. In summary, Ban Pa Phai before crisis phase was totally sufficient for livelihood, with a prosperous environment that sustained production and food security without pressure on market needs. Transition to the crisis phase occurred with the shift to commercial production and interaction with external socio-economic forces from agricultural policies and modernisation. Commercial farming led to production process changes. Multi-dimensions of food insecurity occurred with the shift to new agricultural production patterns, coupled with ecological constraints during the second phase. Farmers showed increased awareness of the problems related to many aspects of their livelihoods. Adaptive production behaviours and collaboration were gradually activated to dynamically respond to food insecurity.

Perception and awareness of villagers to crises are keys for adaptive changes. Based on empirical evidence, socio-economic timelines raise determination as a complex linkage between food security at the macro level and implementation holistically on micro scale. This enables coping mechanisms to mobilise.

Community leaders play an important role in conducting changes and offering solutions to problems through mutual active learning, significantly as motivation of farmers' actions in coping with food and production crises. Moreover, leaders shape collaborative management between people and other supportive organization as networkers who assist in linking vulnerable people with enabling resources and technical experts (facilitators).

Collaborative management between the community with external organisations, shows a vertical relationship regarding local potential on information skill in facilitating activities. Institutional capacity and farmer adaptation were achieved through instigating learning processes and changing operating procedures. Food security outcome are integrated with adaptive production on rice, crops, livestock activities and a wider set of off-farm strategies and resource-based management. Obviously, changing from poor-adopters to better adopters is advantageous to farmers and promotes farming skill and productive procedures. This mechanism increases the effectiveness of development interventions. Here, collaborative management showed constructive changes from passive to proactive by both extension staff and vulnerable people. Significantly, governance and social mechanisms can be adapted effectively.

In this study, sustainability in food security management was implied as a process rather than an end product. Sustaining the capacity for people to deal with crises requires understanding the complexity in casual link dynamics as a bridge spanning adaptive management in specific contexts. Ban Pa Phai presents a good example for other agricultural communities to understand how active dynamic forces in food insecurity can be solved by practical management. Adaptive mechanisms improve farmers' resilience with favourable conservation, economic benefits, cost reduction and food security outcomes.

\section{Acknowledgements}

Sincere gratitude is expressed to Dr Sidthinat Prabudhanitisarn, Assoc Prof Dr Somporn Sa-ngawongse and Assoc Prof Pikul Kowsuwan for their guidance and encouragement throughout this project. Thanks are also due to officials of the Faculty of Social Science, Chiang Mai University and Ban Pa Phai villagers who rendered beneficial co-operation and proactively assisted in this research.

\section{References}

Agranoff, R., \& Mcquire, M. (2003).Collaborative public management: New strategies for local government. Washington, DC: Georgetown University Press.

Barraclough, S. (1991). An end hunger? London: Zed Books.

Berkes, F., \& Folkes, C. (1998). Linking social the ecological systems: management practices and social mechanisms for building resilience. Cambridge: Cambridge University Press.

Creswell, W., \& Clark, P. (2007). Designing on conducting: Mixed method reserch.London: Sage.

Crocker, D. (2008). Ethics of global development: Agency capacity and deliberative democracy. Cambridge: Cambridge 
University Press.

Eakin, H. (2007). Climate change and vulnerability. London: Earthscan.

Etuk, L. (2012). 200 Baseline assessment on rural community vitality. Oregon: Ford Institute.

Food and Agricultural Organisation of the United Nations. (2005). Strengthening resilience for food security and nutrition a conceptual framework for collaboration and partnership among the Rome-based agencies. Rome: Food and Agricultural Organisation of the United Nations.

Food and Agricultural Organisation of the United Nations. (2018). The state of food security and nutrition in the world. Rome: Food and Agricultural Organisation of the United Nations.

Granolati, M. (2005). Improve child nutrition? The integrated child development and services in India. Development and changes 36(4), 613-640. http://doi.org10.111 j.0012155x.2005.00427.x

Gunderson, L. (2006). Adaptive management of environment and adaptive governance in everglades ecosystem. Policy Sciences, 3(4), 323-334.

Hendrix, C. (2012). Climate change, rainfall and social conflict in Africa. Journal of Peace Research, 49(1), 35-50.

Kerdnoi, T., Prabudhanitisarn, S., \& Sangwongse, S. (2014). The struggle of organic rice in Thailand: A multi-level perspective of barrier and opportunities for up scaling. Environment and Natural Resources Journal, 12(1), 95-115. http://www.tci-thaijo.org/inde/php/ennj/article/view/71189

Nystrom, M., \& Folkes, C. (2001). Spatial resilience of coral reefs.Ecosystems, 4, 406-417.

Phungpracha, E., Kansuntisukmomgkon, K., \& Panya, O. (2016).Traditional ecological knowledge in Thailand: Mechanism and contributions to food security. Kasetsart Journal of Social Sciences, 37, 82-87.

Rosset, P. M. (2008). Agroecological versus input substitutions: a fundamental contradiction of sustainable agriculture. http://doi.org 10.1080108941929709381027

Sapbamrer, R. (2004). Health symptoms related to pesticide exposure and agricultural tasks among rice farmers from northern Thailand. Environmental Health and Preventive Medicine, 19, 12-20. http://doi.org/10.1007/s12199-013-0349-3

Sethakul, R. (2009). Socio-economic history of Chiang Mai-Lamphun basin. Bangkok: Silkworm.

Srisomboon, N. (2012). Existing conditions of pesticides poisoning between January and December 2012 in northern Thailand. http://dpc10.ddc.moph.go.th

Thai National Food Committee. (2012). The national food committee strategic framework of food management in Thailand. Bangkok: The Health Promotion Foundation.

Thai Rice Exporters Association. (2018). Rice production ,Thailand. Retrieved September 22, 2018, http:www.thairiceexporters.r.th/production.htm

Thepent, V. (2009). Agricultural mechanisation development in Thailand. Bangkok: Agricultural Engineering Research institute.

Winfuhr, M., \& Jonsen, J. (2005). Food severeignty: toward democracy in localised food system. Bourton on Dunsmore: ITDG Publishing.

\section{Copyrights}

Copyright for this article is retained by the author(s), with first publication rights granted to the journal.

This is an open-access article distributed under the terms and conditions of the Creative Commons Attribution license which permits unrestricted use, distribution, and reproduction in any medium, provided the original work is properly cited. 